\title{
PENGARUH MODEL PEMBELAJARAN DIRECT INSTRUCTION BERBANTU VIDEO PERGERAKAN PROTOZOA TERHADAP HASIL TES SISWA KELAS X IPA 3 SMA NEGERI 3 JEMBER
}

\author{
M. Ubaidilah Hasan ${ }^{1}$ \\ ${ }^{1}$ Institut Pertanian Bogor, Jl. Raya Dramaga, Kampus IPB Dramaga Bogor 16680, \\ Jawa Barat, Indonesia \\ E-mail: ubay.biologi@gmail.com
}

DOI: 10.35719/alveoli.v2i1.37

\begin{abstract}
Direct Instruction is a learning model based on explicit instruction, ongoing support, and student involvement that is compatible with technology-based teaching. One of the direct instruction designs is assisted by video-based on evidence because of effectively and easily reached. This study aimed to describe the effect of direct instruction assisted protozoa movement video on test results. The sample of this study was 33 respondents from students of X IPA 3 class in SMA Negeri 3 Jember. The type of this study was pre-experimental designs (one-group pretest-posttest design). Data were obtained by pretest and posttest, then descriptively analyzed by $\mathrm{R}$ version 4.0.5. This study resulted a minimum score (1) and a maximum score (5) of pretest, a minimum score (4) and a maximum score (5) of posttests, and an average pretest score (3.30) and posttest (4.88). The conclusion of this study was the direct instruction assisted protozoa movement video had improved student test results.
\end{abstract}

Keyword: direct instruction, protozoa movement video, test

\begin{abstract}
Abstrak: Direct Instruction merupakan model pembelajaran berbasis instruksi eksplisit, dukungan berkelanjutan, dan keterlibatan siswa yang sesuai dengan pengajaran berbasis teknologi. Salah satu rancangan model pembelajaran direct instruction ialah berbantu video yang berbasis bukti, karena efektif dan mudah dijangkau. Tujuan penelitian ini ialah mendeskripsikan pengaruh model pembelajaran direct instruction berbantu video pergerakan protozoa terhadap hasil tes. Sampel penelitian ini berjumlah 33 responden dari siswa kelas X IPA 3 SMA Negeri 3 Jember. Jenis penelitian yang digunakan berupa preexperimental designs (one-group pretest-posttest design). Data didapatkan melalui instrumen pretest dan posttest, kemudian dianalisis secara deskriptif dengan aplikasi $\mathrm{R}$ versi 4.0.5. Penelitian ini menghasilkan skor minimal (1) dan skor maksimal (5) pretest, skor minimal (4) dan skor maksimal (5) posttest, dan ratarata skor pretest $(3,30)$ dan posttest $(4,88)$. Kesimpulan penelitian ini ialah model pembelajaran direct instruction berbantu video pergerakan protozoa meningkatkan hasil tes siswa.
\end{abstract}

Kata Kunci: direct instruction, video pergerakan protozoa, tes

Tujuan dari proses pembelajaran adalah kemampuan siswa mengingat, memahami, mengaplikasi, menganalisis, mengevaluasi, dan mencipta berdasarkan materi yang dipelajari. Ketercapaian tujuan belajar siswa tergantung model pembelajaran yang diterapkan. Model pembelajaran memerlukan sistem pengelolaan dan lingkungan belajar yang sedikit berbeda. Oleh sebab itu, guru perlu menguasai dan menerapkan model pembelajaran agar dapat mencapai tujuan pembelajaran yang diinginkan (Budiyanto, 2016: 11). Akan tetapi, masih perlu ditemukan kombinasi yang paling sesuai antara materi dengan model pembelajaran yang digunakan. Hal ini dibuktikan masalah siswa yang cenderung pasif tidak ada respon selama proses pembelajaran berlangsung, seperti tidak ada rasa ingin tahu terhadap apa yang harus 
dipelajari dan dipahamai, karena kegiatan pembelajaran yang biasa mereka lakukan dianggap membosankan, seperti penyampaian materi pembelajaran yang kurang menarik dan variatif (hasil observasi penulis). Dengan demikian, proses pembelajaran seperti ini memengaruhi minat dan prestasi belajar mereka. Agar model pembelajaran terlihat bervariasi dapat dibantu dengan media pembelajaran yang menarik dan menjangkau keterlibatan siswa di dalam kelas. Dengan demikian, siswa tertarik untuk fokus selama proses pembelajaran berlangsung. Selain itu, materi yang disampaikan dapat mudah dipahami secara seksama.

Direct Instruction merupakan model pembelajaran berbasis instruksi eksplisit, dukungan berkelanjutan, dan keterlibatan siswa yang sesuai dengan pengajaran berbasis teknologi (Magliaro, $d k k, 2005:$ 51). Sejak awal ditemukan oleh Engelmann (1960: 4) model ini membutuhkan desain pengajaran yang hati-hati dan pelaksanaan yang terkontrol. Selain itu, model ini efektivitas pendidikan siswa tergantung pada kualitas pengajaran guru yang kompeten dan dilengkapi strategi pengajaran berbasis bukti yang efektif (Ewing, 2011: 68). Model pembelajaran tersebut dapat mengembangkan pengetahuan deklaratif dan pengetahuan prosedural siswa secara terstruktur (Budiyanto, 2016: 11), meningkatkan pemahaman dan hasil belajar secara signifikan (Wijijayanti dan Agustina, 2016: 1), bahkan meningkatkan kemampuan berpikir kritis (Sudarmin, $d k k, 2018: 6)$ dan hasil belajar (Dharmayani, $d k k$, 2019: 45; Warju, $d k k, 2020$ : 79) jika berbantu video. Pemakaian video selain berbasis bukti dan efektif, juga mudah dijangkau. Selain itu, video memiliki nilai khusus bagi siswa dalam pembelajaran biologi (Brame, 2016: 15) dan mampu merangsang memori untuk dapat memiliki kemungkinan lebih tinggi dalam menyimpan materi di memori jangka panjang (Dash, $d k k, 2016: 241)$.

Beberapa studi telah membuat kombinasi antara direct instruction dengan video pembelajaran (Al Maliki, $d k k$, 2014; Sudarmin, $d k k$, 2018; Dharmayanti, $d k k$, 2019; Warju $d k k$. 2020). Namun masih sedikit yang mengkaji pada mata pelajaran Biologi, termasuk materi Protozoa. Padahal, materi ini membutuhkan pemahaman prosedural terkait klasifikasi dan bantuan video tentang ciri yang membedakan antar kelas berdasarkan pola dan alat pergerakan spesiesnya. Berdasarkan pemaparan tersebut, tujuan penelitian ini ialah mendeskripsikan pengaruh model pembelajaran direct instruction berbantu video pergerakan protozoa terhadap hasil tes siswa kelas X IPA 3 SMA Negeri 3 Jember.

\section{METODE}

Penelitian ini menggunakan pendekatan kuantitatif dengan jenis penelitian preexperimental designs (one-group pretest-posttest design) (Sugiyono, 2016: 75) (Tabel 1). Pe- 
nelitian dilakukan pada tanggal 16 Oktober 2018 yang fokus pada populasi siswa kelas X IPA 3 SMA Negeri 3 Jember. Sampel yang diteliti diambil dengan metode sampling jenuh (Sugiyono, 2016: 85), sehingga seluruh siswa (33) tersebut menjadi responden. Setelah sampel diambil, siswa diberi perlakuan berupa sintak model pembelajaran direct instruction berbantu video pergerakan protozoa (dimodifikasi dari Budiyanto, 2016: 66), diantaranya yakni:

(1) Menyampaikan tujuan dan mempersiapkan siswa, termasuk memberikan pretest.

(2) Mendemonstrasikan pengetahuan dan keterampilan berupa video pergerakan protozoa (Gambar 1).

(3) Membimbing pelatihan berdasarkan video pergerakan protozoa.

(4) Mengecek pemahaman dengan posttest dan memberikan umpan balik.

(5) Memberikan kesempatan untuk latihan lanjutan.
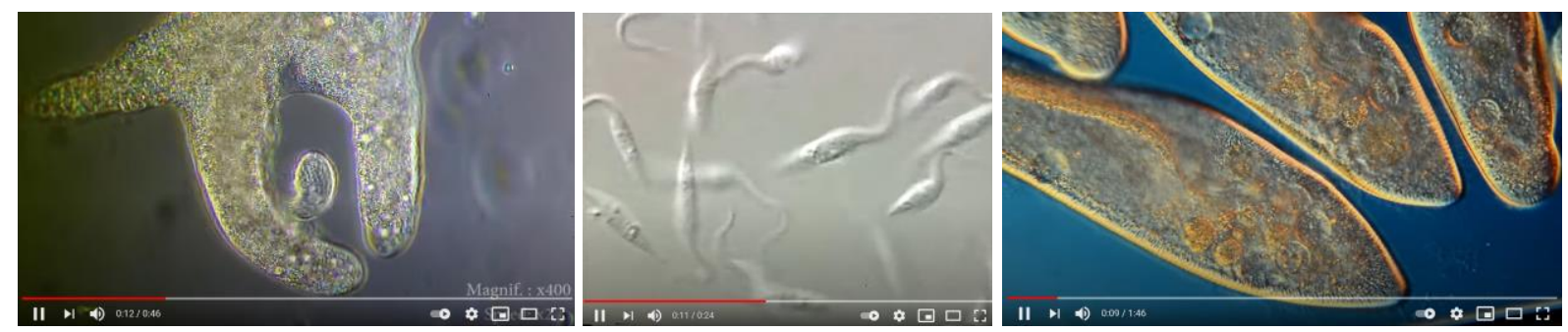

Gambar 1. Tangkapan Layar Video Pergerakan Protozoa (Sarcodina: Loreti/ Kemp[Kiri], Flagellata: Jenni [Tengah]), dan Ciliata: Smith [Kanan]

Tabel 1. Desain pre-experimental designs (one-group pretest-posttest design)

\begin{tabular}{ccc}
\hline Pretest & Treatment & Posttest \\
\hline Y1 & $\mathrm{X}$ & $\mathrm{Y} 2$ \\
\hline
\end{tabular}

Catatan: $\quad \mathrm{Y} 1=$ Pemberian pretest sebelum perlakuan diberikan.

$\mathrm{X}=$ Perlakuan berupa sintak direct instruction berbantu video protozoa

Y2 = Pemberian posttest sesudah perlakuan diberikan.

Instrumen yang digunakan ialah tes objektif berbentuk soal jawaban singkat. Tes tersebut terbagi menjadi dua sesi dengan masing-masing berjumlah 5 butir, yakni tes sebelum perlakuan diberikan (pretest) dan tes sesudah perlakuan diberikan (posttest). Jika satu butir soal dijawab benar diberi skor 1 dan jika salah diberi skor 0. Data yang didapat dianalisis secara deskriptif melalui aplikasi $\mathrm{R}$ versi 4.0.5. 


\section{HASIL}

Penerapan model pembelajaran direct instruction berbantu video pergerakan protozoa telah menunjukkan hasil analisis data sesuai deskripsi pada (Tabel 2).

Tabel 2. Deskripsi Sebaran Jumlah Responden, Nilai Minimum, Nilai Maksimum, RataRata, dan Standar Deviasi dari Masing-Masing Tes

\begin{tabular}{lccccc}
\hline & N & Min. & Max. & Mean & Std. Dev. \\
\hline Pretest & 33 & 1 & 5 & 3,30 & 1,104 \\
Posttest & 33 & 4 & 5 & 4,88 & 0,331 \\
Valid N & 33 & & & & \\
\hline
\end{tabular}

(Tabel 2) menjelaskan bahwa dari 33 responden yang menjawab tes, rata-rata posttestnya lebih besar dari pretest $(4,88 \pm 0,331>3,30 \pm 1,104)$. Selain itu, juga menghasilkan skor minimal yang berbeda $(1 \neq 4)$ dan skor maksimal yang sama $(5=5)$ (Gambar 2). Kenaikan ratarata dari skor prestest ke posttest didukung dengan perbedaan distribusi frekuensi responden dan perolehan skornya pada grafik (Gambar 3).

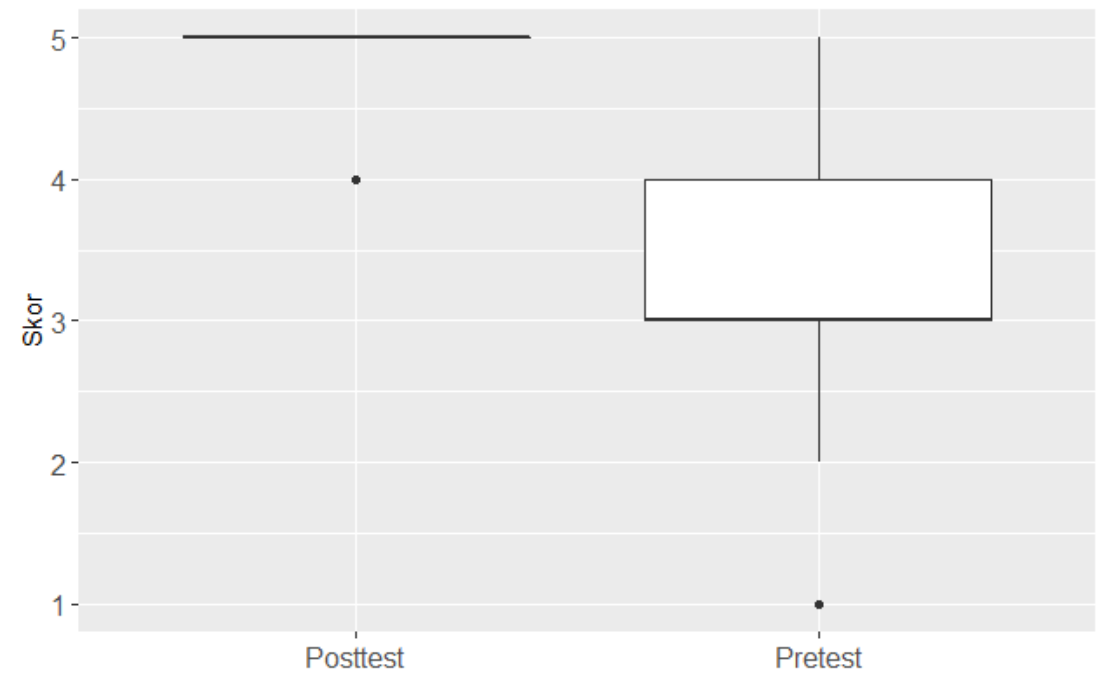

Gambar 2. Boxplot Distribusi Skor Minimal dan Maksimal pada Pretest dan Posttest 


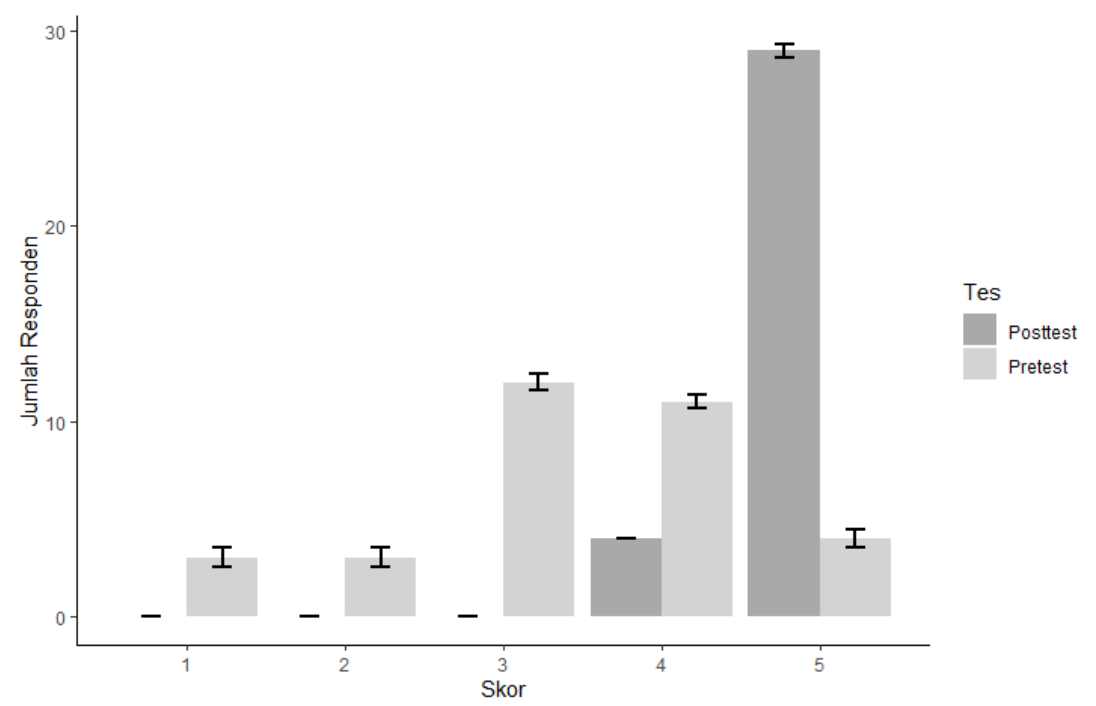

Gambar 3. Grafik Distribusi Perolehan Skor Pretest dan Posttest

Dari 33 responden yang telah menjawab pretest, 3 diantaranya mendapat skor sebesar 1 , 3 diantaranya mendapat skor 2, 12 diantaranya mendapat skor 3, 11 diantaranya mendapat skor 4 , dan 4 diantaranya mendapat skor 5 . Tes yang paling banyak dijawab dengan benar sebanyak 3 butir soal (12 siswa), sedangkan yang paling sedikit 1 dan 2 butir soal (masingmasing 3 siswa) (Gambar 3). Sementara itu, pada posttest menunjukkan visualisasi distribusi perolehan skor dan frekuensi responden yang berbeda. Hal tersebut dibuktikan dengan perolehan dua macam skor saja (4 dan 5). Dari 33 responden yang menjawab posttest, 4 diantaranya memperoleh skor sebesar 4, dan 29 responden sisanya memperoleh skor sebesar 5 (Gambar 3).

\section{PEMBAHASAN}

Direct instruction merupakan model pembelajaran yang berpusat pada guru dan diajarkan secara terstruktur atau langkah demi langkah (Nuraini, 2018: 18). Model ini dapat membuat siswa memahami serta benar-benar mengetahui pengetahuan secara menyeluruh dan aktif. Selain itu, model pembelajaran ini sangat cocok diterapkan di kelas dalam materi tertentu yang bersifat dalil pengetahuan atau bukti ilmiah agar proses berpikir siswa dapat mempunyai keterampilan prosedural (Budiyanto, 2016: 66). Salah satu materi pelajaran yang bersifat dalil pengetahuan ialah materi protozoa pada mata pelajaran biologi.

Dari 33 responden yang diberi perlakukan pembelajaran direct instruction berbantu video pergerakan protozoa, telah menunjukkan adanya kenaikan skor pretest ke skor posttest. Menurut Susiaty (2017: 37) model pembelajaran direct instruction meningkatan prestasi belajar. Jika berbantu video, juga tetap menghasilkan kenaikan rata-rata hasil belajar siswa dari kelas eksperimen (24, 71-79, 29) (Al Maliki, $d k k$, 2014: 169-170). Bahkan, jika tidak 
diberi pretest sekalipun seperti sudi yang dilakukan Dharmayani, dkk (2019: 52), menunjukkan hasil belajar siswa yang lebih tinggi dengan menggunakan model pembelajaran direct instruction berbantuan video $(56,46)$ daripada pembelajaran konvensional $(36,18)$, sekalipun ditinjau dari kompetensi pedagogiknya.

Hasil penelitian ini juga didukung oleh Warju, $d k k$, $(2020 ; 79)$ yang menunjukkan kenaikan ketuntasan pretest (53\%) ke siklus 1 (63\%), hingga siklus 2 (77\%) dari 30 siswa. Jika berbantu media lain yang hampir serupa (simulasi virtual), peningkatan lebih nyata pada kelas eksperimen, yakni dari rata-rata 35,32 ke 65,96 (Arianti, $d k k, 2016$ : 162). Adanya video edukasi memberikan efek visual yang melekat dalam ingatan siswa dalam jangka panjang (long term memory), sehingga materi pelajaran yang disampaikan melalui media video tersebut akan terus diingat oleh siswa (Oka, $d k k, 2018: 117)$. Materi yang terus diingat ini menyebabkan kenaikan hasil tes siswa kelas X IPA 3 SMA Negeri 3 Jember.

Perbedaan rata-rata yang diperoleh dari dua macam tes (pretest dan posttest) didukung dengan perbedaan variasi antara perolehan skornya. Skor posttest variasinya lebih kecil daripada skor pretest. Lebih besarnya skor dan lebih kecilnya variasi posttest yang diperoleh setelah diberi perlakukan menunjukkan penerapan video pergerakan protozoa yang berorientasi model direct instruction dapat meningkatkan kemampuan siswa mempelajari keterampilan prosedural dasar, serta memperoleh pengetahuan deklaratif secara langkah demi langkah berdasarkan video yang ditayangkan. Akan tetapi, pada pretest sebelumnya beberapa siswa mendapat skor terbesar/paling tuntas (5). Tuntasnya skor pretest kemungkinan karena siswa memiliki kemampuan lebih tinggi dibanding yang lain (Utama, $d k k$, 2014: 37). Hal ini terjadi pada 4 siswa kelas X IPA 3 SMA Negeri 3 Jember.

Peningkatan rata-rata skor dari pretest ke posttest membuktikan bahwa model pembelajaran direct instruction memiliki implikasi yang penting dalam mengoptimalkan prestasi siswa (Liem dan Martin, 2013: 5). Selain itu, siswa dapat belajar dengan mengamati secara selektif, mengingat, dan menirukan apa yang diajarkan gurunya. Pengaruh model direct instruction terhadap hasil tes yang diberikan juga membuktikan adanya suasana pembelajaran yang lebih terstruktur karena mengutamakan pendekatan deklaratif dengan titik berat pada proses belajar konsep dan keterampilan motorik (Marlina dan Marwan, 2015: 2). Salah satu bentuk perilaku psikomotorik ialah berkosentrasi menyiapkan diri dan mental terhadap informasi atau bentuk demonstrasi (Prabowo dan Nurmaliyah, 2010: 44). Bentuk informasi/tayangan yang digabungkan dengan model pembelajaran direct instruction ialah video pergerakan Protozoa (Ciliata, Flagellata, dan Sarcodina).

Model pengajaran yang mencakup penggunaan video dapat menjangkau lebih banyak 
siswa dan memberikan lebih banyak peluang dalam mengembangkan memori dan kegiatan pembelajaran (Greenberg, 2012: 19). Oleh sebab itu, implikasi adanya media pembelajaran seperti video dapat membuat siswa menjawab pertanyaan dengan mendapat skor yang lebih tinggi pada tes selanjutnya (Brame, 2016: 5). Hal ini dikarenakan video efektif dalam memvisualisasikan meteri dan membantu menyampaikan materi yang bersifat dinamis (Daryanto, 2013: 88; Dharmayanti, $d k k$. 2019: 47), sehingga siswa dengan mudah memahami dan mengingat materi protozoa, mulai dari klasifikasi hingga perbedaan pola dan alat geraknya.

\section{KESIMPULAN DAN SARAN}

\section{Kesimpulan}

Model pembelajaran direct instruction berbantu video pergerakan protozoa dapat menghasilkan perbedaan hasil tes siswa kelas X IPA 3 SMA Negeri 3 Jember pada materi Protozoa. Perbedaan hasil tes tersebut ditandai dengan adanya kenaikan skor dari pretest ke posttest.

\section{Saran}

Penelitian berikutnya diharapkan dapat membuat kombinasi antara model pembelajaran direct insturction dengan media video yang relevan pada topik dan materi pelajaran lain. Walaupun direct instruction basis pengajarannya terpusat pada guru, pemanfaatan media video sangat membantu siswa menggambarkan imajinasi konsep yang sudah dipahami. Agar siswa bisa lebih terlibat dalam pembelajaran, model direct insturction bisa dikombinasikan dengan model pembelajaran lain dengan tetap memperhatikan media yang digunakan.

\section{DAFTAR RUJUKAN}

Al Maliki IM, Doyan A, dan 'Ardhuha J. "Pengaruh Penerapan Model Pembelajaran Direct Instruction Berbantuan Media Animasi terhadap Hasil Belajar Fisika Siswa Kelas VIII SMP Negeri 1 Batu Layar.” Jurnal Ilmiah Pendidikan Fisika “Lensa”. 2. No 1 (2014): 188-172. doi: 10.33394/j-lkf.v2i1.306.

Arianti BI, Sahidu H, Harjono A, dan Gunawan. "Pengaruh Model Direct Instruction Berbantuan Simulasi Virtual terhadap Penguasaan Konsep Siswa.” Jurnal Pendidikan Fisika dan Teknologi. 2. No 4 (2016): 159-163. doi: 10.29303/jpft.v2i4.307.

Brame CJ. "Effective Educational Videos: Principles and Guidelines for Maximizing Student Learning from Video Content.” CBE-Life Sciences Education. 15. No. 6 (2016): 1-6. doi:10.1187/cbe.16-03-0125. 
Budiyanto AK. 2016. Sintaks 45 Model Pembelajaran dalam Student Centered Learning (CTL). Malang: UMM Press.

Daryanto. 2013. Strategi dan Tahapan Mengajar (Bekal Keterampilan Dasar Bagi Guru). Bandung: CV Yrama Widya.

Dash S, Kamath U, Rao G, Prakash J, and Mishra S. "Audio Visual Aid in Teaching 'Fatty Liver'." Biochemistry and Molecular Biology Education 44 No. 3 (2015): 241-245. doi: 10.1002/bmb.20935.

Dharmayani NKY, Natajaya IN, dan Divayana DGH. "Pengaruh Model Pembelajaran Direct Instruction Berbantuan Video dan Kompetensi Pedagogik Guru terhadap Hasil Belajar Rias Kreatif Siswa Kelas XI Tata Kecantikan Kulit SMK Negeri 2 Singaraja”. Jurnal Administrasi Pendidikan Indonesia 10 No. 1 (2019): 45-55. doi: 10.23887/japi.v10i1.2789.

Engelmann S. 1980. Direct instruction. Englewood Cliffs. New Jersey: Educational Technology.

Ewing B. "Direct Instruction in Mathematics: Issues for Schools with High Indigenous Enrolments: A Literature Review." Australian Journal of Teacher Education 36 No 5 (2011): 56-91.

Greenberg AD, and Zanetis J. 2012. The Impact of Broadcast and Streaming Video in Education. U.S. and other countries: Portion Cisco Systems Inc. and portion Wainhouse Research, LLC. All rights reserved.

Jenni B. "Trypanosoma". https://www.youtube.com/watch?v=P9va64T8H2s [diunggah pada 21 Juni 2012].

Liem GAD, dan Martin AJ. Direct Instruction and Academic Achievement. In International Guide to Student Achievement, by J. Hattie \& E. Anderman (Eds.). Oxford: Routledge. 2013

Loreti T/Kemp M. "Amoeba Eats Paramecia (Amoeba's Lunch) [Amoeba Endocytosis/Phagocytosis Part 1]." https://www.youtube.com/watch?v=mv6Ehv06mXY [diunggah pada 25 Mei 2016].

Magliaro SG, Lockee BB, and Burton JK. "Direct Instruction Revisited: A Key Model for Instructional Technology". ETR\&D. 53. No 4 (2005): 41-55. doi: 10.1007/BF02504684.

Marlina, dan Marwan H. "Pengaruh Penerapan Model Pengajaran Langsung (Direct Instruction) terhadap Hasil Belajar Siswa Kelas X MAN Peudada pada Materi Kebutuhan Manusia”. Jurnal Sains Ekonomi dan Edukasi 3 No. 1 (2015): 1-10. 
Nuraini F, 'Pengaruh Model Pembelajaran Langsung (Direct Instruction) dan Model Pembelajaran Kooperatif Teams Game Tournament (TGT) terhadap Peningkatan Motivasi Belajar dan Penguasaan Konsep Fisika Kelas X MIPA 1 dan Kelas X MIPA 2 SMA Negeri 1 Turi.' Skripsi, Universitas Negeri Yogyakarta. 2018.

Oka DN, Adi NNS, dan Marhaeni IGAND. "Pengaruh Pembelajaran IPA Berbantuan Video Edukasi terhadap Kemampuan Berpikir Kreatif Siswa SMP”. Suluh Pendidikan 16 No. 2 (2018): 113-119.

Prabowo SL, dan Nurmaliyah F. 2010. Perencanaan Pembelajaran Pada Bidang Studi, Bidang Studi Tematik, Muatan Lokal, Kecakapan Hidup, Bimbingan dan Konseling. Malang: UIN-Maliki Press.

Smith C. "How a Paramecium Eats!" https://www.youtube.com/watch?v=sn3MTYNe8mM [diunggah pada 7 Februari 2017].

Sudarmin S, Mursiti S, and Asih AG. "The Use of Scientific Direct Instruction Model with Video Learning of Ethnoscience To Improve Students' Critical Thinking Skills". Journal of Physics Conference Series 1006(1):012011. (2018). 1-7. doi: 10.1088/17426596/1006/1/012011.

Sugiyono. 2016. Metode Penelitian Kuantitatif, Kualitatif, dan R\&D. Bandung: Alfabeta.

Susiaty UD. "Penerapan Model Pembelajaran Direct Instruction (DI) terhadap Prestasi Belajar Mahasiswa Prodi Pendidikan TIK IKIP PGRI Pontianak”. EduSains 5 No. 2 (2017): 33-38. doi: 10.23971/eds.v5i2.735.

Utama C, Kentjananingsih S, dan Rahayu YS. "Penerapan Media Pembelajaran Biologi SMA dengan Menggunakan Model Direct Instruction untuk Meningkatkan Hasil Belajar Siswa”. Jurnal Pena Sains 1, No 1 (2014): 29-39. doi: 10.21107/jps.v1i1.1325.

Warju W, Ariyanto SR, Soeryanto, and Hidayatullah RS. "Practical Learning Innovation: Real Condition Video-Based Direct Instruction Model in Vocational Education”. Journal of Educational Science and Technology 6 No. 1 (2020): 79-91. doi: 10.26858/est.v6i1.12665.

Wijijayanti T, and Agustina Y. "Implementation of Direct Instruction Learning Method to Increase Student's Understanding and Learning Outcome for Company Budgeting Course". Conference: The 2nd International Conference on Elementary and Teacher Education (2016): 1-10. 